\title{
Experiencia de enseñanza-aprendizaje: pandemia covid-19
}

\author{
Ma. del Carmen Nolasco Salcedo
}

\begin{abstract}
Resumen
La emergencia sanitaria por la covid-19 ha desatado un caos en la educación, lo que ha provocado que los docentes universitarios experimenten muchas emociones al tratar de adaptarse a los entornos virtuales, para que sus estudiantes puedan continuar sus clases en cualquier momento y lugar. Esto implica desafíos inéditos, ya que algunos, antes de la pandemia, se resistían a adoptar las plataformas virtuales como una herramienta de apoyo. A pesar de que otros sí aprovecharon los beneficios de estas plataformas, no lo hacían para impartir clases, sino eran sólo un apoyo en la realización de actividades. Se trata de un desafío que los docentes han tratado de superar con empatía, creatividad y esmero, para poder continuar con un proceso de enseñanza-aprendizaje de calidad para sus estudiantes.
\end{abstract}

Palabras clave: educación, covid-19, estudiantes, docentes, ambientes virtuales.

\section{A teACHING-LEARNING EXPERIENCE: THE COVID-19 PANDEMIC}

\begin{abstract}
The health emergency due to the covid-19 has unleashed chaos in education, which has caused university teachers to experience many emotions when trying to adapt to virtual environments, so that their students can continue their courses at any time and place. This implies unprecedented challenges, since some, before the pandemic, were reluctant to adopt virtual platforms as a support tool. Although others did take advantage of the benefits of these platforms, they did not do so to teach classes, but only as a support in carrying out activities. It is a challenge that teachers have tried to overcome with empathy, creativity and dedication, in order to continue with a high quality teaching-learning process for their students.
\end{abstract}

Keywords: education, covid-19, students, teachers, virtual learning environment.

Recepción: 21/10/2020. Aprobación: 1/12/2020. Dol: http://doi.org/10.22201/cuaieed.16076079e.2021.22.1.16 
Profesora e investigadora Titular A, adscrita al Departamento de Ciencias Tecnológicas en el Centro Universitario de la Ciénega, Universidad de Guadalajara. Informática con un Doctorado en Educación por parte de la Universidad Santander en Tamaulipas y una Maestría en Especialidad de Programación por parte de la Universidad Martha Abreu de las Villas, Cuba. En el campo de la programación, ha trabajado en proyectos como: "Sistema de Control de Usuarios del Centro de Cómputo" (siscuc) y "Sistema de Olimpiadas del Saber" (sıos). Ha participado en más de 10 congresos como ponente y ha publicado ocho artículos en los que se encuentran: "Entorno virtual de aprendizaje y cursos en línea: los profesores como factor central" y "'La hora del código' y su impacto en educación preescolar y básica".

nte la emergencia sanitaria que surge a partir de la pandemia generada
por la covid-19, las máximas autoridades universitarias toman de
decisión de cerrar las aulas, lo que me hizo experimentar incertidumbre e inseguridad. La primera porque no tenía la certeza de cuál sería la reacción de los estudiantes en esta nueva modalidad de educación en línea, impuesta por el sistema educativo; la segunda, porque estábamos frente a una situación tensa, de presión y desconfianza respecto a las acciones o decisiones que tomaría como docente en la elaboración de mi curso. No obstante, mi intención era clara: apoyar al estudiante en su proceso de aprendizaje, con empatía y flexibilidad.

En aquellos días, en los que dimos un salto de lo presencial a lo virtual, yo sólo tenía en mente plantear estrategias para lograr captar la atención completa de los estudiantes, el factor más importante de una institución educativa. Por ello, les pregunté qué pensaban de la nueva situación y cómo percibían el trabajo en una aula virtual, después de que todo su proceso de aprendizaje había sido de manera presencial. Escuché sus voces porque era importante saber si estaba fallando como su asesora. Me interesaba conocer si era preciso cambiar de estrategia, o si me hacía falta el ingrediente principal: poner más atención a otros factores de gran importancia, como el desarrollo de las habilidades blandas. 
El trabajar en una plataforma virtual educativa, hacer uso de videoconferencias, desarrollar actividades asíncronas o simplemente entrar al ambiente virtual con los estudiantes, me hizo sentir mariposas en el estómago. Al mismo tiempo, me puso a trabajar en mi pensamiento divergente y me sentía muy motivada porque siempre me ha gustado este estilo de aprendizaje: el hacer uso de la creatividad, el innovar en los procesos de enseñanza a través de las herramientas tecnológicas, fomentar el trabajo colaborativo y estimular en los estudiantes un pensamiento crítico-reflexivo, mientras promuevo su autonomía y protagonismo hasta lograr en ellos un aprendizaje significativo. Así que, poder elaborar mi curso con este nuevo pensamiento fue simplemente genial, fue ser parte de un todo.

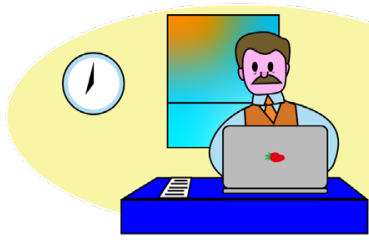

Actualmente, me encuentro inmersa en un pensamiento reflexivo y confirmo que los ambientes virtuales han influido de una manera positiva en mi quehacer docente, al interactuar y socializar más con los estudiantes, al sentir con emoción y satisfacción nuestros logros y al poder fomentarles una competencia de aprender a aprender.

\section{Cómo CITAR ESTE ARTículo}

* Nolasco Salcedo, Ma. del Carmen. (2021, enero-febrero). Experiencia de enseñanza-aprendizaje: pandemia CovID-19. Revista Digital Universitaria (RDU), 22(1). Dol: http://doi.org/10.22201/cuaieed.16076079e.2021.22.1.16 